\section{(C) OPEN ACCESS}

\title{
Hydralazine-associated antineutrophil cytoplasmic antibody vasculitis with pulmonary-renal syndrome
}

\author{
Narothama Reddy Aeddula, ${ }^{1,2}$ Samata Pathireddy, ${ }^{3,4}$ Asif Ansari, ${ }^{5}$ Peter J Juran ${ }^{1,2}$
}

\begin{abstract}
${ }^{1}$ Nephrology, Deaconess Health System, Evansville, Indiana, USA ${ }^{2}$ Medicine, Indiana University School of Medicine, Evansville, Indiana, USA

${ }^{3}$ Internal Medicine, Deaconess Health System, Evansville, Indiana, USA

${ }^{4}$ Medicine, Indiana University School of Medicine, Evansville, Indiana, USA

${ }^{5}$ Nephrology, Permian Basin Kidney Center, Midland, Texas, USA
\end{abstract}

Correspondence to Dr Samata Pathireddy, drspathireddy@gmail.com

Accepted 13 October 2018

Check for updates

(c) BMJ Publishing Group Limited 2018. Re-use permitted under CC BY-NC. No commercial re-use. See rights and permissions. Published by BMJ.

\section{SUMMARY}

Hydralazine, a vasodilator, is commonly used as an adjunctive treatment for moderate to severe hypertension, heart failure and hypertensive emergencies in pregnancy. Hydralazine-induced lupus was first described in 1953. Clinical presentation ranges from arthralgia, myalgia, petechiae, or rash to single or multiorgan involvement. An occurrence of systemic vasculitis is a rare complication. When presented as the pulmonary-renal syndrome, it could have a rapidly progressive course which can be fatal. Here, we describe a case of hydralazine-associated rapidly progressive glomerulonephritis and pulmonary haemorrhage. We use this case to review the current literature and discuss and highlight the importance of a high degree of clinical acumen, early diagnosis and prompt treatment for better clinical outcomes.

\section{BACKGROUND}

Hydralazine was discovered in the 1950s as a treatment for malaria. It is a direct smooth muscle vasodilator used as an adjunctive treatment for moderate to severe hypertension, heart failure with reduced ejection fraction (ACE inhibitor or angiotensin receptor blocker intolerance) and in hypertensive emergencies in pregnancy. ${ }^{1}$ Hydralazine is often implicated as a causal factor in drug-induced lupus. Hydralazine-induced antinuclear cytoplasmic antibody (ANCA) vasculitis (AAV) is a rare phenomenon with pulmonary-renal syndrome with the most severe presentation. The pathogenesis of hydralazine-associated AAV is unknown. Theories for the mechanism of hydralazine-associated AAV include, ${ }^{2}$ (1) hydralazine binding to myeloperoxidase (MPO) leading to neutrophil apoptosis, resulting in the production of multiple autoantibodies; (2) hydralazine-induced reversal of epigenic silencing of MPO and proteinase 3 (PR3) leading to increased expression of neutrophil autoantigens and (3) a break in tolerance in slow versus fast acetylators of hydralazine. ${ }^{3}$ Here, we report a severe complication of hydralazine, presenting as rapidly progressive glomerulonephritis (GN) with pulmonary haemorrhage and discuss the current literature.

\section{CASE PRESENTATION}

A 65-year-old Caucasian woman with a prior history of bilateral clear cell renal cell carcinoma (2013) treated with bilateral open partial nephrectomies, poorly controlled diabetes mellitus over
30 years, hypertension, obesity with prior gastric bypass surgery, progressive proteinuric chronic kidney disease stage 4 , presented to the hospital from home with a 2 day history of shortness of breath and lower extremity swelling and weakness. On presentation, she was afebrile with a blood pressure of $178 / 88 \mathrm{~mm} \mathrm{Hg}$, heart rate of 84 beats/ min, pulse oxygenation of $95 \%$ on $2 \mathrm{~L}$ of $\mathrm{O}_{2}$. The physical was notable for an obese woman with tachypnoea, fine rales and $1+$ pitting pedal oedema. Initial laboratory workup showed a serum creatinine of $6.1 \mathrm{mg} / \mathrm{dL}$ with an estimated glomerular filtration rate of $8 \mathrm{~mL} / \mathrm{min} / 1.73 \mathrm{~m}^{2}$ (eGFR) (calculated using the four-variable modification of diet in renal disease (MDRD) study equation), blood urea nitrogen of $74 \mathrm{mg} / \mathrm{dL}$, potassium of $3.6 \mathrm{mmol} / \mathrm{L}$, haemoglobin of $7 \mathrm{~g} / \mathrm{dL}$, white blood cell count of $6.9 \times 10^{9} / \mathrm{L}$ and platelets of $141 \times 10^{9} /$ L.A urine analysis showed 300 protein, specific gravity of 1.020 , large blood and $>100$ of red blood cells (RBC)/hpf. Chest X-ray was notable for central vascular congestion. A renal ultrasound showed smaller sized kidneys with no hydronephrosis, calculi, with mild to moderate diffuse parenchymal thinning. Her home medications included atorvastatin, bupropion, aspirin, calcitriol, furosemide, hydralazine, Insulin glargine, levothyroxine, mirtazapine, pantoprazole and metoprolol. She was not a smoker with no history of alcohol use. Denied family history of renal disease.

A review of her outpatient laboratories 3 months prior showed a baseline creatinine of $2.4 \mathrm{mg} / \mathrm{dL}$ with corresponding eGFR of $21 \mathrm{~mL} / \mathrm{min} / 1.73 \mathrm{~m}^{2}$ (MDRD). Prior urinalysis was positive for 100 of protein with no RBC or blood. Prior serologies including Hepatitis B Ag, Hepatitis C Ab, HIV and antinuclear antibody (ANA) were all negative. Her spot urine protein creatinine ratio was $2.1 \mathrm{~g}$.

\section{INVESTIGATIONS}

Serological work up, bronchoscopy, CT and renal biopsy.

\section{DIFFERENTIAL DIAGNOSIS}

1. Acute renal failure with pulmonary oedema and uremic haemoptysis.

2. Acute heart failure.

3. Respiratory tract infection with prerenal renal failure and or postinfectious GN.

4. Systemic lupus erythematosus.

5. Cryoglobulinaemic vasculitis. 


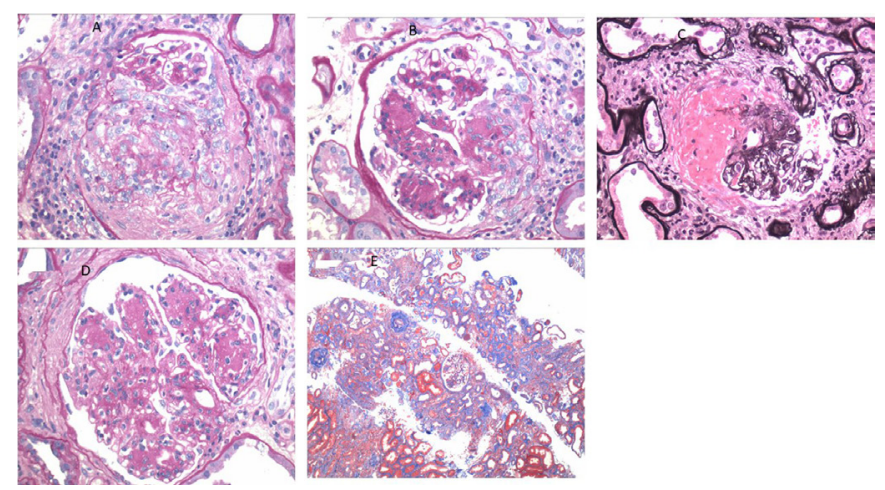

Figure 1 (A)Glomeruli with a fibrocellular crescent (H\&E; original magnification $\times 400)$. (B) Glomeruli with a cellular crescent $(\mathrm{H} \& \mathrm{E}$; original magnification $\times 400)$. (C) Glomeruli with segmental fibrinoid necrosis (methenamine-silver stain; original Magnification x400). (D) Glomeruli with nodular sclerosis (H\&E; original magnification $\times 400)$. (E) Moderate tubular atrophy interstitial fibrosis involving $50 \%$ of the cortical area with moderate interstitial inflammation (Masson's trichrome stain; original Magnification x200).

\section{TREATMENT}

The patient admitted and treated with gentle intravenous fluids and a unit of packed red blood cells. Hydralazine was stopped. Serological workup requested given active urine sediment along with a urological evaluation given the history of renal cell carcinoma. Her erythrocyte sedimentation rate was $>100$. Given the patient's presentation, laboratory parameters with severe renal failure, urine sediment, high inflammatory markers, GN was high on the differential and pulse intravenous steroids administered while waiting for the final serologies and the renal biopsy. Perinuclear antinuclear cytoplasmic antibody titres were 1:40 (reference range $<1: 20$, ARUP Laboratories, Utah, USA), $\mathrm{MPO}$ antibody was positive at $44 \mathrm{AU} / \mathrm{mL}$ (reference range 0-19) and serine protease $3 \mathrm{IgG}$ was $5 \mathrm{AU} / \mathrm{mL}$ (reference range 0-19). ANA and glomerular basement membrane antibody were negative. Complement 3 was $72 \mathrm{mg} / \mathrm{dL}$ (reference range 88-201), Complement 4 was $17 \mathrm{mg} / \mathrm{dL}$ (reference range 10-40). Serum protein electrophoresis and Immunofixation electrophoresis were of the normal pattern. A renal biopsy performed.

The renal biopsy (figure 1) specimen contained 35 glomeruli, 17 of which were globally sclerotic and four were ischaemic. The remaining glomeruli were enlarged and with moderate to severe diffuse and global increase in mesangial matrix and nodule formation. Nine glomeruli had crescents, two of which were cellular, four of which were fibrocellular and three of which were fibrous. Three glomeruli exhibited segmental fibrinoid necrosis. Moderate tubular atrophy and interstitial fibrosis involving $40 \%-50 \%$ of cortical areas with patchy moderate interstitial inflammation by the lymphocytes, plasma cells and monocytes. Severe arteriosclerosis with hyalinosis observed. Immunofluorescence showed weak mesangial staining for IgG, IgA, C3, kappa and lambda, within the spectrum of pauci-immune necrotising crescentic GN. There were low levels of mesangial immune deposits. No definitive immune type electron dense deposits seen.

\section{Diagnosis}

Focal necrotising and crescentic GN, acute and chronic, with low-level immune deposits, superimposed on moderate to severe nodular diabetic glomerulosclerosis with moderate to severe tubular atrophy and interstitial fibrosis.

\section{Clinical follow-up}

The patient was treated with three doses of $1 \mathrm{~g}$ pulse intravenous methylprednisolone followed by oral prednisone $60 \mathrm{mg}$ daily. She was started on rituximab infusions weekly $\left(375 \mathrm{mg} / \mathrm{m}^{2} /\right.$ week) for 4 weeks. She required regular haemodialysis 5 days into her hospitalisation. On day 10 of her hospitalisation, she went into acute hypoxic respiratory failure with a non-contrast CT scan showing diffuse and extensive bilateral lung parenchymal infiltrates throughout lung fields with lung volume loss and pleural fluid. A bronchoscopy showed diffuse alveolar haemorrhage. She further treated with single volume exchange therapeutic plasmapheresis with fresh frozen plasma for seven sessions.

\section{OUTCOME AND FOLLOW-UP}

At the time of writing, the patient remained clinically stable but dependent on haemodialysis therapy for more than 12 months.

\section{DISCUSSION}

AAV is a well-described clinical entity with an incidence of 10-20 cases per million, ${ }^{4}$ though very little is known regarding the prevalence of drug-induced vasculitis. Literature is available relating medications to vasculitis as early as the $1940 \mathrm{s.}^{2}$ This theory was supported after the discovery of ANCAs and their target antigens PR3 and MPO in the 1980s, with case series of patients who were ANCA positive and exposed to medications, such as, hydralazine, allopurinol and propylthiouracil, some developed vasculitis. ${ }^{56}$ Exposure to such drugs can provoke an immune reaction that results in the autoantibodies generation and clinical autoimmune disease, including immune complex or pauci-immune GN. ${ }^{2}$ Evidence of hydralazine-associated vasculitis including rapidly progressive GN dates to the pre-ANCA $\mathrm{era}^{2}$ Hydralazine-induced vasculitis has an incidence of $5.4 \%$ in patients on $100 \mathrm{mg}$ /day to $10.4 \%$ with $200 \mathrm{mg} /$ day for $>3$-years duration, predominantly in patients who are slow acetylators. ${ }^{3}$ Choi et $\mathrm{al}^{7}$ performed a retrospective examination of drug-associated AAV in $250 \mathrm{MPO}$-positive AAV patients. In 30 patients with the maximum anti-MPO antibody titers, 10 patients exposed to hydralazine, of whom nine had renal involvement and five showing renal biopsy-proven pauci-immune necrotizing GN. Yokogawa and Vivino, ${ }^{8}$ in 2009, found 68 hydralazine vasculitis reports. The subjects in the study were predominantly female and had a mean duration of drug exposure of 4.7 years; with a mean dose of $142 \mathrm{mg} /$ day. Renal disease was common on presentation (81\%), and patients had further serological evidence of an autoimmune process (96\% ANA positive, 26\% anti-dsDNA antibody positive and 44\% hypocomplementemia), similar to the previous study by Choi et $a l^{7}$. Kumar et al, ${ }^{9}$ studied 323 cases of AAV of which 12 exposed to hydralazine. Eight out of 12 patients presented with pulmonary infiltrates and one with haemoptysis. Only six patients had a renal biopsy and all of them had pauci-immune crescentic GN. The mean duration of therapy was 22 months with a mean cumulative dose of 146 g. Median age was 70.3 years with all patients being Caucasian with $58.3 \%$ female patients. All 12 patients in the study had elevated anti-MPO antibody.

The identified risk factors that predispose to hydralazine-induced AAV include a cumulative dose of more than $100 \mathrm{~g}$, female gender and thyroid disease. ${ }^{10}$ Other risk factors identified include the human leucocyte antigen (HLA)-DR4 genotype, slow hepatic acetylation and the null gene for $\mathrm{C} 4 .^{11}$

We performed a literature search and in table 1, we reviewed the hydralazine-associated AAV with pulmonary-renal syndrome patients, with only 24 cases reported so far. Seventeen out of 
Table 1 Hydralazine induced antinuclear cytoplasmic antibody vasculitis-patients with the pulmonary-renal syndrome, treatment and outcomes.

\begin{tabular}{|c|c|c|c|c|c|}
\hline Author with reference & Number of patients & $\begin{array}{l}\text { Positive } \\
\text { MPO antibodies }\end{array}$ & $\begin{array}{l}\text { Pulmonary and renal } \\
\text { involvement }\end{array}$ & Treatment & Outcome \\
\hline Almroth et a ${ }^{20}$ & 17 & 12 of 14 tested & 4 & $\begin{array}{l}\text { S } 4 / 4 \\
\text { Cy } 2 / 4 \\
\text { Az } 1 / 4, \\
\text { P } 1 / 4\end{array}$ & $\begin{array}{l}\text { Three out of four } \\
\text { died }\end{array}$ \\
\hline Short and Lockwood ${ }^{23}$ & 10 & 10 & 2 & $\begin{array}{l}\text { S } 2 / 2 \\
\text { Cy } 1 / 2\end{array}$ & Not reported \\
\hline Choi et al ${ }^{7}$ & 10 & 10 & 5 & $\begin{array}{l}\text { S } 5 / 5 \\
\text { Cy } 5 / 5\end{array}$ & One out of four died \\
\hline Yokogawa and Vivino ${ }^{8}$ & 2 & 2 & 1 & $\begin{array}{l}\text { S } 1 / 1 \\
\text { Cy } 1 / 1\end{array}$ & Died \\
\hline Kalra et al ${ }^{24}$ & 1 & 1 & 1 & $\begin{array}{l}\text { S } 1 / 1 \\
\text { Cy } 1 / 1\end{array}$ & Died \\
\hline Babar et al ${ }^{19}$ & 2 & 1 & 1 & $\begin{array}{l}\text { S1/1 } \\
\text { Cy } 1 / 1\end{array}$ & Died \\
\hline Marina et $a l^{17}$ & 1 & 1 & 1 & $\begin{array}{l}\text { S } 1 / 1 \\
\text { Cy } 1 / 1\end{array}$ & Died \\
\hline Agarwal et al ${ }^{25}$ & 1 & 1 & 1 & $\begin{array}{l}\text { S } 1 / 1 \\
\text { Cy } 1 / 1\end{array}$ & Survived \\
\hline Namas et a $\left.\right|^{26}$ & 1 & 1 & 1 & $\begin{array}{l}\text { S } 1 / 1 \\
\text { Cy } 1 / 1 \\
\text { P } 1 / 1\end{array}$ & Survived \\
\hline Rasla et a ${ }^{27}$ & 1 & 1 & 1 & $\begin{array}{l}\text { S1/1 } \\
\text { Cy } 1 / 1 \\
\text { P } 1 / 1\end{array}$ & Survived \\
\hline Kumar et $a l^{9}$ & 12 & 12 of 12 & 6 & $\begin{array}{l}\text { S 5/6 } \\
\text { Cy 5/6 } \\
\text { MM 3/6 }\end{array}$ & Five out of six survived. \\
\hline
\end{tabular}

Az, azathioprine; Cy, cyclophosphamide; MM, mycophenolate mofetil; P, plasmapheresis; S, steroids.

24 patients in the case report survived. Our patient survived, though dependent on the dialysis 12 months after the initial presentation.

The patient in our case had diabetes for more than 30 years. To date, there have been only 10 reported cases of diabetic nephropathy with antineutrophil cytoplasmic antibodies mediated nephritis. ${ }^{12}$ Of the 10 cases, only three cases showed the pathological evidence of diabetic nephropathy. Approximately 20\%-30\% of diabetic nephropathy cases also complicated by nondiabetic nephropathy. ${ }^{13}$ Thus, our case also highlights the need for a higher degree of clinical suspicion in patients with worsening of renal function or abnormal urinalysis that does not concur with the natural course of diabetic nephropathy.

The mechanisms of hydralazine-associated AAV pathogenesis is not clear. In vivo study data suggests that ANCAs are by themselves pathogenic. ${ }^{14} \mathrm{MPO}$ knockout mice that lack functioning B- and T-lymphocytes, when injected with anti-MPO splenocytes, developed severe necrotizing crescentic GN and haemorrhagic pulmonary capillaritis. It's hypothesised that hydralazine collects in neutrophils and binds to MPO, this induces neutrophil apoptosis and cytotoxic products which further act as a source of immunogens as apparent by the presence of numerous antibodies that associated with hydralazine-induced AAV. ${ }^{15}$ The antibodies either alone or by a complex interaction with infectious agents or genetic factors may contribute to the disease. A study done by Magro et al suggested that hydralazine interferes with neutrophil extracellular traps (NETs), which leads to further uptake of previously sequestered antigens. ${ }^{16}$ Antibodies associated with hydralazine-induced vasculitis include MPO-ANCA, ANA, antihistone antibody, antielastase antibody and antiphospholipid antibody. ${ }^{15} 17$ Antihistone antibody is commonly seen with drug-induced vasculitis and is absent with ANCA-associated vasculitis. ${ }^{14}$ The combination of antihistone antibody, MPO and/ or PR3 ANCA and absence of anti dsDNA antibody could be used to support the diagnosis of hydralazine-induced vasculitis in the appropriate clinical setting with evidence of pauci-immune GN. ${ }^{18}$ As the presence of multi-antigenicity is a key finding, multiple serological markers should raise suspicion for drug-induced vasculitis. ${ }^{19}$ Presence of very high MPO antibody titers is another distinct characteristic of drug-induced pauci-immune GN. ${ }^{7}$

The infrequency of drug-induced AAV and overlying features with idiopathic vasculitis is the greater dilemma in early diagnosis. ${ }^{19}$ The diagnosis relies mainly on constitutional and system-specific symptoms, exhaustive medication history, the total duration of drug therapy, the presence of serological markers and the resolution of symptoms after discontinuation of the offending drug. ${ }^{19}$ Patients with hydralazine-associated vasculitis characteristically have a more severe course, predominantly due to renal vasculitis and therefore require more aggressive treatment. ${ }^{8}$ Concomitant occurrence of pulmonary haemorrhage is the most powerful predictor of death, ${ }^{20}{ }^{21}$ necessitating early diagnosis and prompt initiation of treatment. For a definitive diagnosis, a renal biopsy is strongly encouraged which also ascertains the severity of disease and aids in prognostication. Apart from a detailed history, laboratory and pathological findings, the Naranjo adverse drug reaction probability scale was used in our case, which specified that the association of hydralazine to pulmonary-renal syndrome was probable. ${ }^{22}$

Currently, no guidelines are available and no randomised controlled trials conducted in the treatment of hydralazine and other drug associated AAV. Treatment should individualise to the patient, based on the age, disease severity, co-morbidities and renal function on presentation. In mild cases, discontinuing the 
offending medication may lead to resolution of AAV. In severe cases, particularly with pulmonary or renal involvement, aggressive management with immunosuppressive regimens are needed for hydralazine and drug-mediated AAV. Corticosteroids with cyclophosphamide or rituximab and therapeutic plasma exchange for the pulmonary haemorrhage and rapidly progressive GN should consider. Immunosuppression should be individualised, preferable with a regimen with fewer side effects and a shorter duration of treatment. It is important to educate the patients about the future drug exposure, with the index drug added to the allergies list in the patient's medical record. Further studies to better understand the etiopathogenesis of hydralazine-AAV is warranted to invent better markers for diagnosis and treatment.

\section{Learning points}

- Hydralazine-induced antinuclear cytoplasmic antibody vasculitis and pulmonary-renal syndrome though rare, can be rapidly progressive and fatal.

- A thorough clinical and medication history, serologies and pulmonary-renal pathological findings can help in the diagnosis.

- Treatment includes stopping the hydralazine, appropriate use of immunosuppressants based on the severity and therapeutic plasmapheresis.

Acknowledgements We would like to thank Dr Dominick Santorielli, MD, Assistant Professor of Pathology and Cell Biology, Columbia University, New York, for the renal biopsy pathology and images.

Contributors NRA, SP, AA and PJJ involved in the planning, conception, acquisition of data and helped with the final drafting of the case report. SP and NRA are the first authors and have equally contributed to the majority of the article.

Funding The authors have not declared a specific grant for this research from any funding agency in the public, commercial or not-for-profit sectors.

Competing interests None declared.

Patient consent Not required.

Provenance and peer review Not commissioned; externally peer reviewed.

Open access This is an open access article distributed in accordance with the Creative Commons Attribution Non Commercial (CC BY-NC 4.0) license, which permits others to distribute, remix, adapt, build upon this work non-commercially, and license their derivative works on different terms, provided the original work is properly cited and the use is non-commercial. See: http://creativecommons.org/ licenses/by-nc/4.0/

\section{REFERENCES}

1 Farag M, Mabote T, Shoaib A, et al. Hydralazine and nitrates alone or combined for the management of chronic heart failure: A systematic review. Int J Cardiol 2015; 196:61-9.

2 Hogan JJ, Markowitz GS, Radhakrishnan J. Drug-induced glomerular disease: immunemediated injury. Clin J Am Soc Nephrol 2015;10:1300-10.
3 Pendergraft WF, Niles JL. Trojan horses: drug culprits associated with antineutrophil cytoplasmic autoantibody (ANCA) vasculitis. Curr Opin Rheumatol 2014;26:42-9.

4 Ntatsaki E, Watts RA, Scott DG. Epidemiology of ANCA-associated vasculitis. Rheum Dis Clin North Am 2010;36:447-61.

5 Nässberger L, Sjöholm AG, Jonsson H, et al. Autoantibodies against neutrophil cytoplasm components in systemic lupus erythematosus and in hydralazine-induced lupus. Clin Exp Immunol 1990;81:380-3.

6 Dolman KM, Gans RO, Vervaat TJ, et al. Vasculitis and antineutrophil cytoplasmic autoantibodies associated with propylthiouracil therapy. Lancet 1993;342:651-2.

7 Choi HK, Merkel PA, Walker AM, et al. Drug-associated antineutrophil cytoplasmic antibody-positive vasculitis: prevalence among patients with high titers of antimyeloperoxidase antibodies. Arthritis Rheum 2000;43:405.

8 Yokogawa N, Vivino FB. Hydralazine-induced autoimmune disease: comparison to idiopathic lupus and ANCA-positive vasculitis. Mod Rheumatol 2009;19:338-47.

9 Kumar B, Strouse J, Swee M, et al. Hydralazine-associated vasculitis: Overlapping features of drug-induced lupus and vasculitis. Semin Arthritis Rheum 2018;5:1.

10 Lionaki S, Hogan SL, Falk RJ, et al. Association between thyroid disease and its treatment with ANCA small-vessel vasculitis: a case-control study. Nephrol Dial Transplant 2007;22:3508-15.

11 McKinnon RA, Nebert DW. Possible role of cytochromes P450 in lupus erythematosus and related disorders. Lupus 1994;3:473-8.

12 Nishino T, Minami K, Uramatsu T, et al. An elderly patient with diabetic nephropathy complicated by ANCA-associated nephritis. Intern Med 2012:51:1227-32.

13 Olsen S, Mogensen CE. How often is NIDDM complicated with non-diabetic renal disease? An analysis of renal biopsies and the literature. Diabetologia 1996;39:163845.

14 Xiao H, Heeringa P, Hu P, et al. Antineutrophil cytoplasmic autoantibodies specific for myeloperoxidase cause glomerulonephritis and vasculitis in mice. J Clin Invest 2002;110:955-63.

15 Jiang X, Khursigara G, Rubin RL. Transformation of lupus-inducing drugs to cytotoxic products by activated neutrophils. Science 1994;266:810-3.

16 Magro CM, Momtahen S, Harp J. The distinctive histopathology of hydralazineassociated ANCA positive vasculitis: in vivo demonstration of NETosis. Eur J Dermatol 2017;27:91-92.

17 Marina VP, Malhotra D, Kaw D. Hydralazine-induced ANCA vasculitis with pulmonary renal syndrome: a rare clinical presentation. Int Urol Nephrol 2012;44:1907-9.

18 Radić M, Martinović Kaliterna D, Radić J. Drug-induced vasculitis: a clinical and pathological review. Neth J Med 2012;70:12-7

19 Babar F, Posner JN, Obah EA. Hydralazine-induced pauci-immune glomerulonephritis: intriguing case series with misleading diagnoses. J Community Hosp Intern Med Perspect 2016;6:30632

20 Almroth G, Eneström S, Hed J, et al. Autoantibodies to leucocyte antigens in hydralazine-associated nephritis. J Intern Med 1992;231:37-42.

21 Hogan SL, Nachman PH, Wilkman AS, et al. Prognostic markers in patients with antineutrophil cytoplasmic autoantibody-associated microscopic polyangiitis and glomerulonephritis. J Am Soc Nephrol 1996;7:23-32.

22 Naranjo CA, Busto U, Sellers EM, et al. A method for estimating the probability of adverse drug reactions. Clin Pharmacol Ther 1981;30:239-45.

23 Short AK, Lockwood CM. Antigen specificity in hydralazine associated ANCA positive systemic vasculitis. QJM 1995;88:775-83.

24 Kalra A, Yokogawa N, Raja H, et al. Hydralazine-induced pulmonary-renal syndrome: a case report. Am J Ther 2012;19:e136-8.

25 Agarwal G, Sultan G, Werner SL, et al. Hydralazine induces myeloperoxidase and proteinase 3 anti-neutrophil cytoplasmic antibody vasculitis and leads to pulmonary renal syndrome. Case Rep Nephrol 2014;2014:1-4.

26 Namas R, Rubin B, Adwar W, et al. A challenging twist in pulmonary renal syndrome. Case Rep Rheumatol 2014;2014:1-4.

27 Rasla S, El Meligy A, Cucu DF. Hydralazine-Induced ANCA Vasculitis in the Setting of Acute Clostridium Difficile Infection. R I Med J 2016;99:41-3.

Copyright 2018 BMJ Publishing Group. All rights reserved. For permission to reuse any of this content visit

https://www.bmj.com/company/products-services/rights-and-licensing/permissions/

BMJ Case Report Fellows may re-use this article for personal use and teaching without any further permission.

Become a Fellow of BMJ Case Reports today and you can:

- Submit as many cases as you like

- Enjoy fast sympathetic peer review and rapid publication of accepted articles

- Access all the published articles

Re-use any of the published material for personal use and teaching without further permission

For information on Institutional Fellowships contact consortiasales@bmjgroup.com

Visit casereports.bmj.com for more articles like this and to become a Fellow 